\title{
Isolation of Variant Strains from Foot-and-Mouth Disease Virus Propagated in Cell Cultures Containing Antiviral Sera
}

\author{
By N. ST G. HYSLOP \\ The Animal Virus Research Institute, Pirbright, Woking, Surrey
}

(Received 23 April 1965)

\section{SUMMARY}

Three strains of foot-and-mouth disease virus of type SAT 1 were propagated serially in cultures of pig kidney cells in the presence of gradually increased concentrations of specific antiserum. All showed an increase in their ability to multiply in the presence of the serum. With two of the strains, complement-fixation tests revealed that propagation under these conditions was associated with modification of antigenic structure, but antigenic differences were detected later than changes in the ability of all strains to multiply in the presence of antiserum. Processes of this nature may possibly result in vivo from similar interactions of virus and antibody in host populations.

\section{INTRODUCTION}

Within each of the seven principal types of foot-and-mouth disease virus certain strains have been isolated which differ from one another in their host-specificity, virulence and invasiveness. In addition to differences of this nature, dissimilarity in antigenic constitution is frequently detectable by complement-fixation tests and other methods. The accumulated evidence for the existence of field strains possessing antigenic differences sufficiently great to justify their classification as subtypes was reviewed in a previous report (Hyslop, Davie \& Carter, 1963); that report also described the practical effect of subtype variants on the apparent efficacy of vaccination campaigns. The influences which lead to the emergence of subtype variants in the field remain obscure but the interplay of infection and immunity in the host population is probably an important factor. The present report records the isolation of variants from three strains of foot-and-mouth disease virus, which were each passaged serially in secondary monolayer cultures of pig kidney cells in the presence of gradually increasing concentrations of antisera specific for the original strains.

\section{METHODS}

Foot-and-mouth disease (FMD) virus. All strains were of type SAT 1. Strain RV. 11/37 was isolated in Southern Rhodesia in 1937, strain SA. 13/61 was isolated in the Transvaal in 1961 and strain Tur. 323/62 was isolated in western Turkey during the epizootic of 1962 . Before passage in pig-kidney tissue culture, the 3 strains were each propagated on the tongues of cattle at Pirbright and then were typed by complement-fixation tests.

Titration. Serial threefold dilutions of virus were inoculated intraperitoneally into randomized groups of 4- to 6-day-old albino mice of the Pirbright ' $P$ ' strain. 
Usually 8 mice were inoculated with each dilution and the $50 \%$ fatality end-points were estimated by the method of Kärber (1931).

Hyperimmune guinea pig sera. Virus strains were usually passaged twice in guinea pigs before being used to produce hyperimmune sera. Groups of guinea pigs, of about $500 \mathrm{~g}$. body weight, from the colony at this Institute, were hyperimmunized by two doses of virus suspension. The first intradermal inoculation into the tarsal pads contained $0.05 \%(w / v)$ saponin; this was followed after 21 days by an intramuscular inoculation (without saponin). The animals were bled out 10 days later.

Hyperimmune cattle serum. Virus of strain Tur. 323/62 passaged in cattle was inoculated into the dermal mucosa of a fully susceptible steer, which developed clinical foot-and-mouth disease. A second inoculation of virus of the same strain was made 76 days later. The animal was bled for serum 2 weeks after the second inoculation.

Propagation of virus in pig-kidney tissue culture. Pig kidney cells, grown as primary monolayers for 6-7 days in Roux flasks containing Earle's saline with 0.5\% lactalbumin hydrolysate and $0.01 \%$ yeast extract (EYL medium) plus $10 \%$ bovine serum, were harvested by means of $0.02 \%$ EDTA + trypsin solution and, after washing, were seeded into $4 \mathrm{oz}$. flat bottles containing the same medium. After about 2 days of incubation at $37^{\circ}$ the secondary monolayers were washed and warm fresh medium, usually containing the required concentration of either inhibitory or normal serum, was added. The culture was inoculated with virus and incubation continued until either cytopathic effect was observed or the medium became acid.

Complement-fixation tests. Guinea pig hyperimmune sera were prepared by using virus isolated at several passage stages during propagation in pig-kidney tissue cultures containing antisera; similar sera were prepared at the corresponding passage stages in which identical amounts of normal serum had been incorporated in the medium. The sera were used in complement-fixation tests (Brooksby, 1952; Bradish \& Brooksby, 1960) to determine the cross-fixation ratios of the various virus isolates with one another. The cross fixation ratio is:

Amount of complement fixed in the heterologous serum-virus system

Calculation of the product of these ratios excludes differences attributable to the relative concentrations of individual reagents. Some degree of antigenic variation was indicated when the product of these ratios was significantly less than unity; and when the product was less than $\mathbf{0 . 5}$ strains were considered to be distinct subtypes (Bradish \& Brooksby, 1960).

Serum-virus neutralization tests. Cross-neutralization tests in mice, using homologous and heterologous substrain-specific sera, were done by the method of Skinner (1953).

\section{RESULTS}

Strain RV. 11/37

Cattle-passaged FMD virus of strain RV. 11/37 was passaged once in mice and a Seitz EK filtrate (infectivity titre $10^{5-4}$ mouse $\mathrm{LD} \mathrm{50} / \mathrm{ml}$.) was prepared from triturated mouse carcasses. Equal volumes of the filtrate and of a $10^{-5.0}$ dilution 
of guinea pig hyperimmune serum (homologous strain) were mixed and incubated for $30 \mathrm{~min}$. at $26^{\circ}$. Two $\mathrm{ml}$. of the mixture were inoculated into a pig-kidney tissue culture monolayer; the same volume of virus mixed with $0.4 \mathrm{M}$-phosphate buffer (pH 7-6) was inoculated into a further pig-kidney tissue culture monolayer. After $30 \mathrm{~min}$. incubation, the monolayers were washed and $20 \mathrm{ml}$. EYL medium added. Cytopathic effect was evident in both cultures after incubation for $24 \mathrm{hr}$ at $37^{\circ}$ and the culture fluids were used to inoculate the next cultures of the series. The procedure was repeated 4 times, the serum concentration being increased tenfold at each stage.

After the 5th passage, virus and serum were not mixed before the cultures were inoculated, but the serum was added directly to the culture medium and then $1 \mathrm{ml}$. of virus suspension was added to $19 \mathrm{ml}$. of the serum +medium mixture. A further 41 passages of strain RV. 11/37 A were made in medium containing guinea pig hyperimmune serum at a dilution of $\mathbf{1 0}^{-\mathbf{2} \cdot 0}$, followed by four passages in which the dilution was decreased to $10^{-1 \cdot 7}$. At the 1st, 5th, 31st and 46th passages the amounts of virus inoculated were $10^{5 \cdot 7}, 10^{6.5}, 10^{6.4}$ and $10^{5.3}$ mouse LD 50. Concurrently, substrain RV. 11/37 B was passaged in medium containing corresponding dilutions of normal serum for a total of 50 passages.

Table 1. Decrease of the neutralizing power of 1/1000 antiserum for foot-and-mouth disease virus strain RV.11/37 propagated serially in pig-kidney tissue culture containing homologous antiserum

\begin{tabular}{|c|c|c|c|}
\hline \multirow[b]{2}{*}{$\begin{array}{c}\text { Passage } \\
\text { no. }\end{array}$} & \multicolumn{2}{|c|}{$\begin{array}{l}\text { Log. depression of virus } \\
\text { titre after } 30 \mathrm{~min} . \\
\text { incubation with antiserum }\end{array}$} & \multirow{2}{*}{$\begin{array}{l}\text { Log. } \\
\text { difference } \\
\text { between } \\
\text { virus } \\
\text { substrains }\end{array}$} \\
\hline & Substrain A & Substrain B & \\
\hline 1 & $2 \cdot 2$ & $\mathbf{1} \cdot \mathbf{9}$ & $\leqslant 0 \cdot 0$ \\
\hline 4 & $1 \cdot 8$ & $2 \cdot 6$ & 0.8 \\
\hline 10 & $1 \cdot 8$ & $\mathbf{2} \cdot \mathbf{3}$ & 0.5 \\
\hline 30 & $1 \cdot 5$ & $2 \cdot 3$ & 0.8 \\
\hline 45 & 0.6 & $2 \cdot 6$ & $2 \cdot 0$ \\
\hline
\end{tabular}

Substrain A, passaged in the presence of immune serum; substrain B, passaged in the presence of normal serum.

Sensitivity to incubation with antiserum. The sensitivities of the two substrains to the neutralizing effect of RV. 11/37 guinea pig hyperimmune serum were compared at intervals during the experiment, the first and last isolates being passaged once in serum-free cultures before being used for neutralization tests. Virus suspensions were mixed with equal volumes of a 1/500 dilution of serum in $0.4 \mathrm{M}$-phosphate buffer ( $\mathrm{pH} \mathrm{7 \cdot 6)}$ and, after incubation for $30 \mathrm{~min}$. at $37^{\circ}$, the two mixtures and serum-free controls were titrated in mice. Little change occurred in the sensitivity of substrain RV. 11/37 A before the 30th passage but the substrain became much less susceptible to inactivation by serum between the 30th and 45th passages (Table 1).

Complement-fixation tests. Because the virus suspensions harvested from the 50th pig-kidney tissue culture were consistently anticomplementary, both substrains were passaged once on the tarsal pads of guinea pigs to produce antigen suitable for 
complement-fixation tests. The cross-fixation product of substrains RV. 11/37 A and RV. 11/37 B was 0.03 , indicating that the substrains were antigenically distinct after the 50th passage.

\section{Strain $S A .13 / 61$}

A 1/10 suspension of bovine tongue epithelium infected with FMD virus of strain SA. 13/61 was filtered and $2 \mathrm{ml}$. samples used to inoculate two pig-kidney tissue culture monolayers maintained in $18 \mathrm{ml}$. EYL medium. To these cultures had been added either (A) pooled serum from cattle recovered from clinical infection with virus of strain SA. 13/61, or (B) normal cattle serum, in volumes sufficient to produce a final dilution of serum of $10^{-5 \cdot 0}$. Only limited cytopathic effect was noted after incubation for $24 \mathrm{hr}$ but virus from each of the cultures was passaged serially in gradually increasing concentrations of the appropriate sera. At the start of the experiment the strain did not multiply in the presence of immune serum at a dilution of $10^{-4 \cdot 0}$. Serial passage of the substrains continued until strain SA. 13/61 A had been passaged twice in the presence of convalescent serum concentrations of $10^{-5 \cdot 0}$, once at each of the concentrations $10^{-4 \cdot 0}, 10^{-3 \cdot 0}, 10^{-2 \cdot 0}$, and $10^{-1 \cdot 7}$ and finally 4 times at a serum concentration of $10^{-1 \cdot 5}$. Substrain SA. 13/61 B was passaged similarly in the presence of normal serum. Although the presence of increasing amounts of antiserum during serial passage appeared to exert progressively less inhibitory effect on the virus, ten passages were insufficient to cause significant change either in the sensitivity to incubation with $1 / 1000$ antiserum or in the antigenic structure of the substrain $\mathbf{A}$.

Strain Tur. 323/62

The general procedure followed that of the previous experiment but hyperimmune cattle serum was employed instead of convalescent serum. The initial inoculum was a filtrate from a suspension of triturated bovine tongue epithelium infected with strain Tur. 323/62; the infectivity titre was $10^{5 \cdot 5}$ mouse LD 50/ml.

Substrain Tur. 323/62 A was passaged in pig-kidney tissue culture 3 times in the presence of a serum dilution of $10^{-4 \cdot 0}$, twice at a dilution of $10^{-3 \cdot 0}, 5$ times at $10^{-2 \cdot 5}$, 5 times at $10^{-2 \cdot 3}, 3$ times at $10^{-1 \cdot 7}$ and then twice at a serum dilution of $10^{-1 \cdot 5}$. Substrain Tur. 323/62 B was passaged concurrently in the presence of corresponding dilutions of pooled serum from normal cattle. Well-marked cytopathic effect was observed with both substrains. After the 20th passage the substrains were stored at $-20^{\circ}$ pending completion of the complement-fixation tests. The stored material was revived by a single passage in serum-free pig-kidney tissue culture; then a further five passages were made in a serum concentration of $10^{-1.5}$ and at each stage an attempt was made to propagate virus of substrain Tur. 323/62 A in a serum concentration of $10^{-1.8}$ (Table 2). The effect is not attributable to a gradual increase in the infectivity titre of the inoculum during passage.

Sensitivity to incubation with antiserum. Virus from the 1st, 10th, 15th and 20th passage levels of substrains Tur. 323/62 A and Tur. 323/62 B were each passaged once in serum-free pig-kidney tissue culture and then used in cross-neutralization tests against homologous and heterologous guinea pig sera. Modification occurred in substrain Tur. 323/62 A between the 15th and 20th passages and this was sufficient to cause a difference greater than tenfold in the neutralization indices of the homologous and heterologous serum + virus pairs (Table 3). 
Variant strains of $F M D$ virus

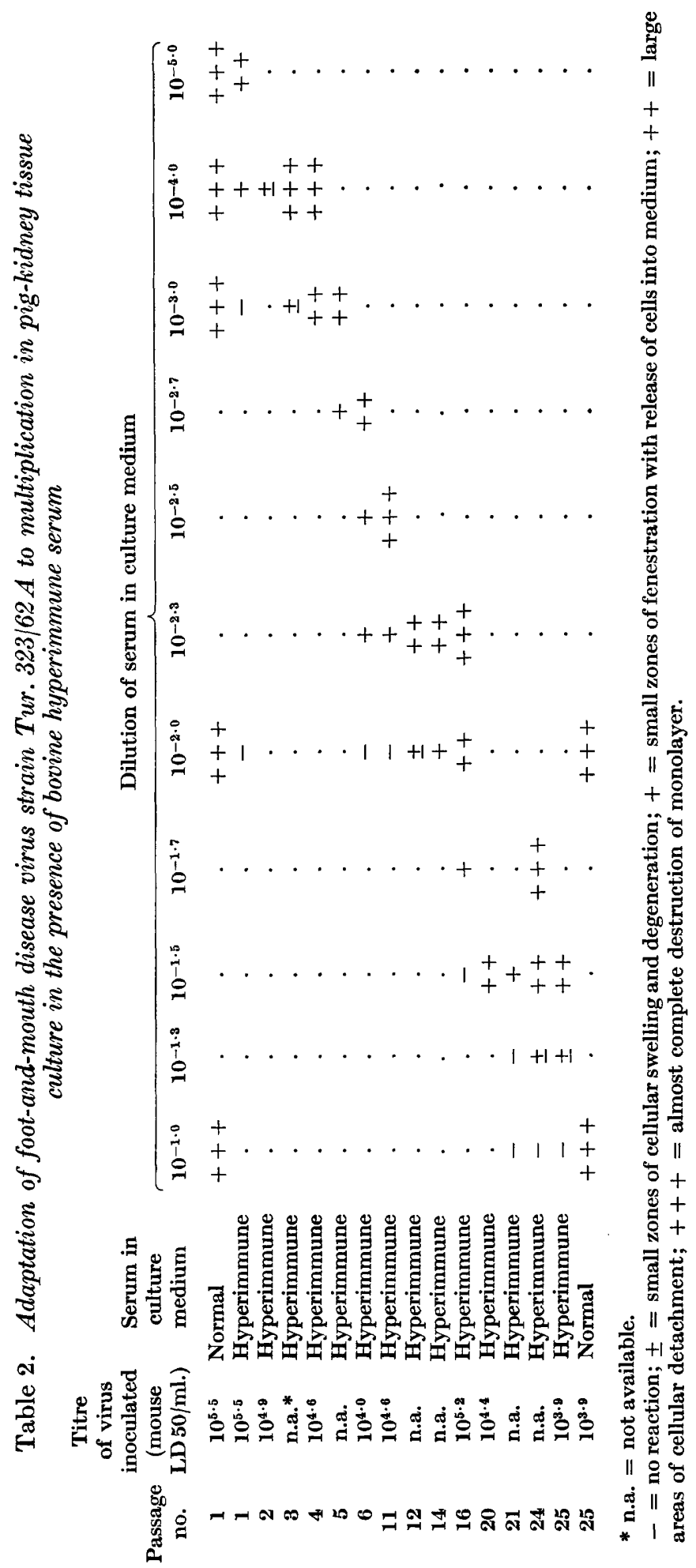


Complement-fixation tests. Virus suspensions collected at several passage levels were used as antigens for complement-fixation tests with homologous and heterologous antisera; a significant difference in the amount of complement fixed was not observed, irrespective of whether supernatant or whole-culture material was employed. Little change in antigenic structure was detectable during the first $\mathbf{1 5}$ passages (Table 4), though some modification may have occurred already in the ability of substrain Tur. 323/62 A to multiply in the presence of hyperimmune cattle serum (Table 2). By the 15th passage, however, antigenic differences were just becoming apparent. After the 20th passage the mean cross-fixation product of the substrains had decreased to $0 \cdot 4$ and they may be regarded as distinct strains. The 1st and 20th passages of substrain Tur. 323/62 B were antigenically similar.

Table 3. Cross-neutralization indices (log.) of substrains of foot-and-mouth disease virus strain Tur. 323/62 in neutralization tests with homologous and heterologous antisera

\begin{tabular}{|c|c|c|c|c|}
\hline \multirow{2}{*}{$\begin{array}{c}\text { Virus, } \\
\text { substrain } \\
\text { and } \\
\text { passage } \\
\text { no. }\end{array}$} & \multirow{2}{*}{ Serum, } & \multicolumn{3}{|c|}{ substrain and passage no. } \\
\hline & & A1 & B 20 & A 20 \\
\hline B1 & $3 \cdot 2$ & $\mathbf{3} \cdot \mathbf{3}$ & $3 \cdot 4$ & 1.5 \\
\hline A1 & $3 \cdot 5$ & $\mathbf{3} \cdot \mathbf{3}$ & $4 \cdot 2$ & 1.5 \\
\hline A 10 & $\mathbf{3 \cdot 5}$ & $\mathbf{3 . 5}$ & $3 \cdot 8$ & $1 \cdot 6$ \\
\hline A15 & $3 \cdot 2$ & $3 \cdot 2$ & $3 \cdot 4$ & $2 \cdot 4$ \\
\hline A 20 & $2 \cdot 2$ & $2 \cdot 1$ & $2 \cdot 4$ & $3 \cdot 5$ \\
\hline B 20 & 3.5 & $\mathbf{3 . 3}$ & 3.7 & 1.9 \\
\hline
\end{tabular}

Substrain A, passaged in the presence of immune serum; substrain B, passaged in the presence of normal serum.

Table 4. Complement-fixation products of substrains $\boldsymbol{A}$ and $\boldsymbol{B}$ of foot-and-mouth disease virus strain Tur. 323/62 during pig-kidney tissue culture passage in hyperimmune serum and in normal serum, respectively

\begin{tabular}{|c|c|c|c|c|c|c|c|c|c|c|}
\hline \multirow{2}{*}{$\begin{array}{c}\text { Substrain } \\
\text { and } \\
\text { passage } \\
\text { no. }\end{array}$} & \multicolumn{10}{|c|}{ Substrain and passage no. } \\
\hline & B1 & A1 & B5 & A5 & B 10 & A 10 & B15 & A15 & B20 & A20 \\
\hline B1 & 1.00 & 1.00 & 1.03 & 0.96 & 1.02 & . & 0.90 & . & $1 \cdot 00$ & 0.37 \\
\hline A1 & 1.00 & $1 \cdot 00$ & . & . & . & . & . & . & . & . \\
\hline B5 & 1.03 & . & $1 \cdot 00$ & $1 \cdot 00$ & . & . & . & . & . & . \\
\hline A5 & 0.96 & . & 1.00 & 1.00 & . & . & . & . & . & . \\
\hline B 10 & 1.02 & . & . & . & 1.00 & 0.96 & . & . & . & . \\
\hline A10 & . & . & . & . & 0.96 & 1.00 & . & . & . & . \\
\hline B 15 & 0.90 & . & . & . & . & . & 1.00 & 0.80 & . & . \\
\hline A 15 & . & . & . & . & . & . & 0.80 & 1.00 & . & . \\
\hline B20 & 1.00 & . & . & . & . & . & . & . & 1.00 & 0.40 \\
\hline A20 & 0.37 & . & . & . & . & . & . & . & 0.40 & 1.00 \\
\hline
\end{tabular}

Substrain A, passaged in the presence of immune serum; substrain B, passaged in the presence of normal serum.

\section{DISCUSSION}

The availability of a strain-specific antiserum of high titre prompted the use of guinea pig serum for the early experiments with foot-and-mouth disease (FMD) virus strain $R V .11 / 37$ but, in an attempt to relate experiments in vitro more 
closely to the conditions which might occur in vivo, strains SA. 13/61 and Tur. 323/62 were passaged with bovine sera. Because of this and other differences in technique, comparison between strains is rendered difficult. Irrespective of the source of antiserum, however, propagation of FMD virus of type SAT 1 in the presence of subinhibitory concentrations of homologous antibody was associated with gradual change in one or more of the characteristics of the strains. Thus, by the 50th passage in the presence of guinea pig hyperimmune serum, a very profound change in both serum sensitivity and antigenic structure had occurred in substrain A of strain RV. 11/37. Similar modification occurred during 20 passages of strain Tur. 323/62 in pig-kidney tissue cultures containing cattle hyperimmune serum. With strain SA. 13/61 the changes were limited to an apparent increase in the ability of the strain to multiply in greater concentrations of antiserum.

By the 5th passage, the substrain Tur. $323 / 62 \mathrm{~A}$ was able to multiply in a concentration of hyperimmune serum at least 12 -fold greater than at the 1st passage (Table 2). Complement-fixation tests did not reveal any antigenic modification until the 10th passage, when the difference in cross-fixation product was of doubtful significance. Although 20 passages apparently modified the antigenic constitution of the strain sufficiently for it to be considered distinct from the original strain, it cannot be concluded that as many as 20 passages would necessarily be required to produce such an effect on this or on other strains. The rate of change of substrain Tur. 323/62 A was greatest between the 16th and 20th passages, when the antiserum dilution was $10^{-1 \cdot 7}$ or less (Tables 2 and 3 ); it might well have been possible to propagate the virus in lower dilutions of serum at a somewhat earlier stage and thus to have accelerated the rate of antigenic variation. However, because the animal providing the antiserum had been inoculated twice with virulent virus, the neutralizing titre of its serum was $\geqslant 1 / 4096$ and this precluded the use of low dilutions of serum in the early passages. There was no evidence that passage in pig-kidney tissue culture containing normal serum decreased the sensitivity of the strain to immune serum or caused modification of antigenic structure.

The data from these experiments do not reveal the mechanism by which the variants arose. Because field strains of virus were used to initiate each passage series, the new substrains may have been isolated either as a result of mutation or by selection from an originally heterogeneous population. The alternatives are not mutually exclusive but, partly because of the progressive nature of the changes observed, it appears less likely that selection from a mixed population was the predominant factor in the isolation of variants. In this context it is noteworthy that strain Tur. 323/62 and other strains isolated at about the same time, during the epizootic in the Middle East, have all shown evidence of remarkable stability and antigenic similarity; and strain RV. 11/37 has been maintained for more than 25 years at Pirbright without exhibiting any obvious 'drift' in its properties. Stability of the degree exhibited by these strains appears inconsistent with very heterogeneous populations and it is likely that mutants begin to form an important fraction of the population only when adverse factors tend to suppress the original strain.

Selection may greatly alter the frequency of one-step mutants during relatively few passages and it is relevant to recall that the mutation rate for marker systems such as thermal inactivation may be as high as $10^{-3 \cdot 8}$ to $10^{-5 \cdot 6}$ for some strains of 
foot-and-mouth disease virus (Pringle, 1964). Furthermore, Pringle (1965) has indicated that the differences between strains which are revealed by complementfixation tests are a manifestation of a complex genetic characteristic. Consequently, it is probable that the variation in subtype characters observed in the present experiments occurred principally as a result of cumulative selection of a number of independent mutations during serial passage in the strongly selective system employed. Moreover, recent experiments of a similar nature (to be reported elsewhere) indicate that virus of plaque-purified strains may also develop, during relatively few passages, a marked increase in ability to grow in the presence of antiserum prepared against virus from the same clone. Changes in antigenic structure, resembling those reported above, were detected subsequently during experimental passage of foot-and-mouth disease virus in partly immunized cattle (Hyslop \& Fagg, 1965).

The author wishes to thank Mr R. H. Fagg, who supervised most of the complement-fixation tests, and to acknowledge the technical assistance of Mr R. L. G. King and Mr K. C. Cranston.

\section{REFERENCES}

Bradish, C. J. \& Brooksby, J. B. (1960). Complement-fixation studies of the specificity of the interactions between components of the virus system of foot-and-mouth disease and its antibodies. J. gen. Microbiol. 22, 405.

Brooksby, J. B. (1952). The technique of complement fixation in foot-and-mouth disease research. A.R.C. Rep. Ser. no. 12.

Hyslop, N. St G., Davie, J. \& Carter, S. P. (1963). Antigenic differences between strains of foot-and-mouth disease virus of type SAT 1. J. Hyg., Camb. 61, 217.

Hyslop, N. ST G. \& FAGG, R. H. (1965). Isolation of variants during passage of a strain of foot-and-mouth disease virus in partly immunized cattle. J. Hyg., Camb. (in the Press).

KäRBER, G. (1931). Beitrag zur kollektiven Behandlung pharmakologischer Reihenversuche. Arch. exp. Path. Pharmak. 162, 480.

Pringle, C. R. (1964). Genetic aspects of the thermal inactivation properties of foot-andmouth disease virus strains. Bull. Off. int. Epiz. 61, 619.

Pringle, C. R. (1965). Evidence of genetic recombination in foot-and-mouth disease virus. Virology, 25, 48.

SkINNER, H. H. (1953). One week old white mice as test animals in foot-and-mouth disease research. Proc. XV int. vet. Congr., Stockholm, 1953, p. 208. 